\title{
Business strategy: a study on cost stickiness behavior
}

\author{
Permata Ayu Widyasari \\ University of Surabaya, Surabaya, Indonesia
}

\begin{abstract}
This paper examined the effect of firm-level business strategies on the stickiness of Selling and Administrative cost in manufacturing firms. It applied business strategies scoring model developed by Bentley et al. (2013). This model transforms the firm's financial data into business strategy classification based on Miles and Snow typology. This paper focused on prospectors and defender business strategy and its behavior regarding expense stickiness. Prospectors are characterized as innovation-oriented firms and tend to modify their product market-mix rapidly, while defenders are characterized as a more stable company that compete on the basis of price, and focusing on a narrow product base. This paper found that defender (less innovative) business strategy reduces the expense stickiness on Selling and Administrative expense. Such findings add the explanation in respect of asymmetric cost behavior such as the expense stickiness phenomenon.
\end{abstract}

Keywords: Business strategy, defender, expense stickiness, prospector.

\section{INTRODUCTION}

This paper documents that in increasing 1\% of sales, the selling and administrative cost increase about $20.6 \%$. However, in the decreasing of $1 \%$ sales, the SG\&A only falls by $2.8 \%$. It shows an asymmetric cost behavior, called as expense stickiness.

Costs are sticky if the magnitude of the increase in cost associated with an increase in volume is greater than the magnitude of the decrease in cost associated with an equivalent decrease volume (Anderson et al. 2003).

The existence of expense stickiness is strongly connected to management's active behavior (Anderson et al. 2003; Xue \& Hong 2016). The stickiness of SG\&A cost occurs if managers decide to retain un-utilized resources when volume declines, rather than suffer adjustment cost (Anderson et al., 2003). Adjustment cost includes severance payment for dismissed employee and hiring and training cost for the new employee when the sales increases again. In addition, Adjustment cost includes organizational cost such as loss of morale among remaining employees when associates are terminated or erosion of human capital when work teams are disrupted (Anderson et al., 2003). Other scholars have suggested that managers tend to be optimistic about future rev- enue because most firms' future revenues increase, making them reluctant to reduce expenses (Xue \& Hong, 2016).

Compared with the classic linear cost behavior model described by traditional management accounting, expense stickiness fits better with the management decision of resource adjustment in practice. (Xue \& Hong 2016).

Manager's decision is aligned with the company's business strategy. Each business strategy has distinctive strategic focus - the root of the competitive advantage of the company-. Prospector business strategy focuses on market innovation, while defender business strategy focuses on efficiency and stability (Bentley et al. 2013).

Prospector Company seeks and exploits new products and market opportunities. Therefore, it invests heavily in research and development and has a strong focus on marketing effort. Defender emphasizes cost minimization of the production and distribution of goods and services. It minimizes the marketing-related activities. It has strict capital expenditure and prefers to utilize the available asset. (Bentley et al. 2013)

The inherent characteristic of business strategy may formalize the manager's decision regarding adjustment cost, the cause of expense stickiness. 
Knowing the effect of asymmetric cost behavior caused by manager's decision, the importance of observing the influence of company's business strategy towards asymmetric cost behavior such as expense stickiness occurs. This study proposed that business strategy does have the impact on the expense stickiness. Based on the distinctive characteristic, the defender will have lower expense stickiness compared to the prospector. Prospector company tends to be more optimistic and has the urge to catch the opportunity, making them reluctant to forgone the underutilize resource making them behaving cost stickiness. In contrast, Defenders focuses on cost minimization, so they avoid the underutilization of resource making them have anti-stickiness cost.

This paper contributed to the understanding that business strategy affects the asymmetric cost behavior. It elaborated the manager's decision based on business strategy model and the consequence that matters to expense stickiness. Understanding the cost behavior leads to better budgeting, better forecasting and allocating resource more efficiently. However, Expense stickiness might be a distraction for allocating resource efficiently.

\section{LITERATURE REVIEW}

Business strategy is a consistent set of decisions that define how a firm competes within a given industry or product market (Varadarajan \& Clark 1994; Walker Jr \& Ruekert 1987)

The main differences between prospector and defender can be analyzed based on their strategic focus; operating strategy; and its products.

Prospector focuses on market innovation. As a result of focusing on development and innovation orientation, prospector's product tends to be unique and without viable substitutes. It rapidly changes their product-market mix to be innovative market-leaders in numerous domains. It executes operating strategy that seeks and exploits new products and market opportunities. Consequently, it invests heavily in research and development and has a strong focus on marketing effort. It often engages in new opportunities even before detailed planning is completed. It must adapt well to uncertainty. Besides, it has numerous business units which require decentralized control and collaboration among business unit (Miles \& Snow 2003; Bentley et al. 2013; Higgins et al. 2015).

Defender focuses on efficiency and stability. It executes operating strategy that emphasizes cost minimization of the production and distribution of goods and services. Defender maintains a narrow and stable product focus to compete on the basis of price, service, or quality. It has strict capital expenditure, minimizes the marketing-related activities and prefers to utilize the available asset. It requires certainty in future outcomes and often engages in detailed planning before undertaking new opportunities. It has a high degree of mechanization and routinization and tends to invest in a single core cost-efficient technology. The defender has a centralized organizational structure to ensure the operating efficiency. Executive and employee's tenure is lengthy, and managers are promoted from within the firm. (Miles \& Snow 2003, Bentley et al. 2013, Higgins et al. 2015)

As the declining sales, the uses of the resource will drop, in fact, some resource should be eased. Otherwise, it will lead to underutilized resources. Inherently, Prospector Company has an urge to stay alert to catch the opportunity when the sales increase again or when there is a new opportunity. Prospector company is demanded to react to this opportunity quickly. The adjustment cost such as hiring and training new workers may lead to losing the chance. Keeping the underutilized employee is the preferable alternative for Prospector Company.

Prospector Company has strong marketing effort. Even in declining sales, prospector declines to reduce the resource, including the resource in the marketing department. Armanto et al. (2015) stated that business which requires many employees in sales and marketing department, usually behave sticky cost. In addition, more permanent staffs in sales and marketing will directly increase the fixed cost and create sticky cost behavior.

In contrast, defender emphasizes cost minimization and has strict capital expenditure. So, the manager prefers to utilize the available asset and avoid the underutilized resources. In addition, it minimizes the marketing-related activities and denotes have fewer permanent staff in sales and marketing. Therefore, compared to Prospector Company, the defender company will face lower stickiness expense.

H1: defender business strategy decreases the expense stickiness of selling and administrative cost

\section{RESEARCH METHODS}

This paper interpreted business strategy as the way a firm competes in an industry or market. The manufacturing industry is able to capture firm's strategy in terms of handling product-market change, customers and competitors. In addition, Armanto et al. (2015) find that compared to other industries, SGA costs in manufacturing industry (consists of basic industry and chemicals, miscellaneous industry, and consumer goods industry) tend to behave sticky. 
Therefore, manufacturing industry is a suitable sample for this study. This study used Indonesia manufacturing firms listed on Indonesia Stock Exchange (IDX) during 2011 -2015. The samples used in this study were 495 firm-years.

With the aim to catch the extreme condition, this research dichotomized the business strategy into prospector and defender by Miles \& Snow (2003). Following Bentley et al. (2013), this study gathered six components of business strategies. Each component is ranked per industry - per year and scored based on five quintiles. Those observations in the highest quintiles are scored 5; those in the second highest quintile are scored 4; and so on until the lowest quintiles are scored 1 (except capital intensity which is reversed-scored). The scores are summed over the six proxies. A firm can receive a maximum score of 30 and a minimum score of 6 .

Next, business strategy is defined based on a composite of six business strategy components. This paper dichotomized the total score of composite business strategy proxies by assigning a value of 1 (prospector) if the total score is $\geq$ the median, and 0 (defender) if it is below the median. The explanation of business strategy's components as a follow:

$$
\begin{aligned}
& \text { RnD Intens } \quad=\frac{\text { RnD Expense }}{\text { Sales }} \\
& \text { Employee Intensity }=\frac{\text { Number of Employees }}{\text { Sales }} \\
& \text { Sales Growth } \quad=\frac{\text { Sales }_{t}-\text { Sales }_{t-1}}{\text { Sales }_{t-1}} \\
& \text { Sales Effort } \quad=\frac{\text { Selling,general and Admin expense }}{\text { Sales }} \\
& \text { Employee Fluctuation }=\frac{\text { Employee }_{t}-\text { Employee }_{t-1}}{\text { Employee }_{t-1}} \\
& \text { Capital Intensity } \quad=\frac{P P E}{\text { Total Asset }}
\end{aligned}
$$

Regression equation (1) is used to test the effect of business strategy in overcome the expense stickiness.

$$
\begin{aligned}
\log \left[\frac{S G A i, t}{S G A i, t-1}\right]= & \beta 0+\beta 1 \log \left[\frac{R E V i, t}{R E V i, t-1}\right] \\
& +\beta 2 \log \left[\frac{R E V i, t}{R E V i, t-1}\right] * \text { DUMrev } \\
& +\beta 3 \log \left[\frac{R E V i, t}{R E V i, t-1}\right] * \text { DUMrev } \\
& * \text { DumBisStrat }
\end{aligned}
$$

\section{RESULT AND DISCUSSION}

This research initiated the hypothesis testing by comparing means between the defenders and prospectors. Table 1 and table 2 show the test of independent sample t-test and Mann-Whitney U-test re-

\begin{tabular}{|c|c|c|c|c|c|}
\hline & \multicolumn{2}{|c|}{ Defender } & \multicolumn{2}{|c|}{ Prospector } & \multirow[b]{2}{*}{ Z } \\
\hline & $\begin{array}{l}\text { Mean } \\
\text { rank }\end{array}$ & $\mathrm{N}$ & $\begin{array}{l}\text { Mean } \\
\text { rank }\end{array}$ & $\mathrm{N}$ & \\
\hline $\begin{array}{l}\log \left[\frac{R E V i, t}{R E V i, t-1}\right] \\
* \text { DUMrev }\end{array}$ & 220.69 & 284 & 285.76 & 212 & $-6.088 * * *$ \\
\hline
\end{tabular}

spectively. Based on t-test, $\log \left[\frac{\text { REV } i, t}{R E V i, t-1}\right] *$ DUMrev (represent the expense stickiness), the expense stickiness between two groups is different. Both t-test and Mann-Whitney test indicate that the level expense stickiness between prospector and defender is different.

Table 1. Independent sample t-test

\begin{tabular}{llllll}
\hline & Defender & \multicolumn{3}{c}{ Prospector } & \multirow{2}{*}{$\mathrm{t}$} \\
\cline { 2 - 5 } & Mean & $\mathrm{N}$ & Mean & $\mathrm{N}$ & \\
\hline $\begin{array}{l}\text { Log }\left[\frac{R E V i, t}{R E V i, t-1}\right] \\
\text { * DUMrev }\end{array}$ & -.0695 & 284 & -.0337 & 212 & $-2.854^{* * *}$ \\
\hline
\end{tabular}

Table 2. Mann-Whitney U-test

Based on table 3 panel a, the value of $\beta 1$ show coefficient 0.206 significant. It indicates that every $1 \%$ of increasing sales revenue, the SG\&A will increase about $20.6 \%$. The coefficient of $\beta 2$ shows a significant negative sign at $10 \%$ significance level. It points out the existence of expense stickiness. Combine the value of $\beta 1$ and $\beta 2(0.206$ and $-0.178=$ 0.028 ), it clarifies that when the sales revenue decreased by $1 \%$, the SG\&A decreased by $2.8 \%$. Moreover, the $\beta 3$ show the interaction with business strategy. The significant positive sign of $\beta 3$ indicates that defender business strategy is able to decrease the expense stickiness.

Table 3. Regression test

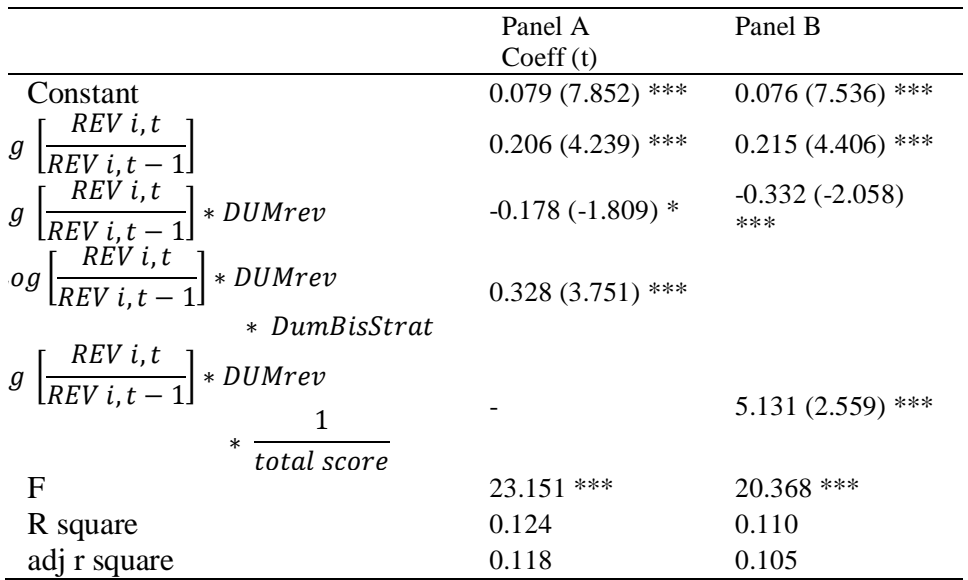

Since the scoring system by Bentley et.al (2013) shows higher score mean prospector, the reversing scoring is used in the additional test. 1/ score is used to reflect the higher score show more defender. If the hypothesis is hold, the $\beta 4$ in equation 2 should be a significant positive. 
Based on table 3 panel b, the negative significant sign of $\beta 2$ represents the existence of expense stickiness, moreover, the significant positive of $\beta 4$ indicates that the interaction with defender business strategy does decrease the expense stickiness. The higher reverse scoring may reduce the expense stickiness. Means, the more company executes the defender business strategy, the more the expense stickiness is reduced.

$$
\begin{aligned}
\log \left[\frac{S G A i, t}{S G A i, t-1}\right]= & \beta 0+\beta 1 \log \left[\frac{R E V i, t}{R E V i, t-1}\right] \\
& +\beta 2 \log \left[\frac{R E V i, t}{R E V i, t-1}\right] * \text { DUMrev } \\
& +\beta 3 \log \left[\frac{R E V i, t}{R E V i, t-1}\right] * \text { DUMrev } \\
& * \text { DumBisStrat .... (2) }
\end{aligned}
$$

In In conclusion, by dichotomy and by scoring (reverse) shows that defender business strategy decreases the expense stickiness of SG\&A expense of manufacturing company.

\section{CONCLUSION}

Prospector company suffers expense stickiness due to its manager's perception regarding underutilized resource during declining sales and adjustment cost when the sales are recovered. Prospector Company has an urge to catch opportunities. Even during sales declining, dropping the employee to avoid underutilizes resources is an unfavorable choice. It creates cost stickiness. As the implication, managers of prospector company may consider professional outsourced employees to fulfill the uncertain condition.

\section{REFERENCES}

Anderson, M. C., Banker, R. D. \& Janakiraman, S. N. 2003. Are selling, general, and administrative costs "sticky"? Journal of Accounting Research 41(1): 47-63.

Armanto, B., Tiono, K. M. \& Suthiono, H. 2015. The Stickiness of Selling, General, and Administrative Costs in the Indonesian Companies. International Research Journal of Business Studies 7(1): 39-53

Bentley, K. A., Omer, T. C. \& Sharp, N. Y. 2013. Business strategy, financial reporting irregularities, and audit effort. Contemporary Accounting Research 30(2): 780-817.

Higgins, D., Omer, T. C. \& Phillips, J. D. 2015. The influence of a firm's business strategy on its tax aggressiveness. Contemporary Accounting Research 32(2): 674-702.

Miles, R. E. \& Snow, C. C. 2003. Organizational Strategy, Structure, and Process. Stanford: Stanford University Press.

Varadarajan, P. R. \& Clark, T. 1994. Delineating the scope of corporate, business, and marketing strategy. Journal of Business Research 31(2): 93-105.
Walker Jr, O. C. \& Ruekert, R. W. 1987. Marketing's role in the implementation of business strategies: a critical review and conceptual framework. The Journal of Marketing 1533.

Xue, S. \& Hong, Y. 2016. Earnings management, corporate governance and expense stickiness. China Journal of Accounting Research 9(1): 41-58. 